\title{
NOTE TO THE EDITOR: \\ ON THE INVERSION OF LAPLACE TRANSFORMS BY THE METHOD OF PAPOULIS*
}

\author{
BY T. Z. FAHIDY (University of Waterloo, Waterloo, Ontario, Canada)
}

In a paper published in this journal [1], A. Papoulis presented a numerical inversion technique for Laplace transformation by means of a trigonometric approach.

It is clear by inspection that Eq. (34) is a nonsequitur; a $\pi / 4$ factor is missing in the summation term and the first binomial coefficient should correctly read

$$
\left(\begin{array}{c}
2 n \\
n-j
\end{array}\right)
$$

Further, the entry for $C_{0}$ at $n=4$ in Table 1 in (1) that contains the binomial coefficients of $C_{k}$ is incorrectly given as 19 . The correct value is

$$
\left(\begin{array}{l}
8 \\
4
\end{array}\right)-\left(\begin{array}{l}
8 \\
3
\end{array}\right)=70-56=14
$$

Further, in Example 2 the correct value of $C_{10}$ is 15.953 instead of 0.0982 originally reported; truncation of Eq. (2) is necessary at the ninth term in this case.

\section{ReFerences}

[1] A. Papoulis, A new method of inversion of the Laplace transform, Quart. Appl. Math. 14, 405 (1957)

*Received May 5, 1967. 